\begin{tabular}{|c|c|c|c|c|c|c|c|}
\hline THE & SOCIETY & FOR & HEALTHCARE & \multicolumn{2}{|c|}{ EPIDEMIOLOGY } & OF & AMERICA \\
\hline President & \multicolumn{3}{|c|}{ Bryan I? Simmons, MD/Memphis, Tennessee } & TREASURER & \multicolumn{3}{|c|}{ Elias Abrutyn. MD/Philadelphia, Pennsylvania } \\
\hline PRESIDENT-ElectT & \multicolumn{3}{|c|}{ William J. Mat-tone, MD/Atlanta, Georgia } & COUNCILOR & \multicolumn{3}{|c|}{ Edward S. Wong, MD/Richmond, Virginia } \\
\hline Vice President & \multicolumn{3}{|c|}{ Robert A. Weinstein, MD/Chicago, Illinois } & CouncILOR & \multicolumn{3}{|c|}{ Leigh G. Donowitz, MD/Charlottesville, Virginia } \\
\hline Past President & \multicolumn{3}{|c|}{ Peter A. Gross, MD/Hackensack, New Jersey } & Councilor & \multirow{2}{*}{\multicolumn{3}{|c|}{ Timothy W. Lane, MD/Greensboro, North Carolina }} \\
\hline SECRETARY & \multicolumn{3}{|c|}{ Dale N. Gerding, MD/Chicago, Illinois } & Councilor & & & \\
\hline
\end{tabular}

\title{
Record Number of Abstracts Received for SHEA Annual Meeting in San Diego
}

A record number of abstracts was sub mitted for the Annual Meeting to be held next month in San Diego, and the quality of the abstracts also has continued to improve. An unprecedented number of abstracts (54) will be presented in slide sessions, and another 140 will be presented in the poster sessions on Sunday and Monday. For the first time, for the convenience of meeting attendees, box lunches will be provided in the exhibit hall so that attendees may eat lunch and view the posters at the same time. In addition to the presentation of 194 abstracts, there will be three plenary sessions, eight symposia, and ten "Meet the Consultant" sessions (each given twice). The SHEA Lecture will be given by Dr. Philip S. Brachman. This lecture will be followed by the presentation of the SHEA Young Investigator and SHEA Trainee Awards. The second day of the meeting will be topped off by the Late Breaker Session and, for members, the SHEA Business Meeting.

Social functions include a cocktail reception on Sunday evening and a ticketed event on Monday evening, "Adventure at the Zoo." The latter event will take place at the world-famous San Diego Zoo. Animal trainers will wander through the party to present animals "up close and personal." Hors d'oeu- vres, drinks, and music at the multilevel Treetops Restaurant are included. Tickets are \$39 for adults and \$34 for children under 12.

Join your friends and colleagues in San Diego at the Fifth Annual Meeting of SHEA. Bring the whole family for a minivacation and take advantage of the many sites and attractions of San Diego. This is an excellent meeting to take in new scientific data on the cutting edge in hospital epidemiology and infection control, renew old acquaintances among your colleagues, and enjoy the scenery and attractions of one of America's favorite vacation spots.

\section{Conference on Managed Care in Infectious Diseases Planned for June 9-10, 1995}

A conference on managed care in infectious diseases (ID) is planned for Friday, June 9, and Saturday, June 10, at the Westin Hotel in Chicago. The conference is designed to guide ID specialists in how to deal with the changes, challenges, and opportunities of managed care and healthcare reform.

The focus will be on quality assurance, outcomes monitoring, formulary management, infection control, and the potential role of the infectious diseases specialist in managed care. Physicians with first-hand knowledge in these areas will share their experiences and also will lead a work shop on the development of a model contract.
The conference is sponsored by the Clinical Affairs Committee of the Infectious Diseases Society of America, the Society for Healthcare Epidemiology of America, Inc. (SHEA), and the Outpatient Intravenous Infusion Therapy Association (OPIVITA).

The first day will begin with a review of ongoing changes in health care from the perspectives of the government, insurers, healthcare organizations, physicians, and attorneys. In the afternoon, there will be presentations by infectious diseases specialists with positive experiences in the areas of consultative services, hospital epidemiology, outpatient IV therapy, and HIV care.

On Saturday morning, the tools of contracting will be explored. There will be presentations on computer use, outcomes monitoring, and legal issues. In the afternoon, there will be workshops designed to teach skills needed for developing proposals for services for reimbursement, negotiating with payors, and developing contracts.

The conference is being organized by Alan Tice, Tom Slama, and Steve Berman. If you have any questions, or if you have not yet received a brochure about the conference, please call (206) 627-7137, or fax (206) 572-2470.

Brief items of interest for the SHEA N ews may be sent to $C$. Glen Mayhall, M D. FAX: (409) 772-6527. 
SATURDAY, APRIL 1, 1995

Workshop 1:

Computers in Infection Control

Workshop 2:

Issues in Development and Use of Indicators

SUNDAY, APRIL 2 - TUESDAY, APRIL 4, 1995

PLENARY SESSIONS:

Control of Antibiotic Resistant Organisms

- Where Have our Hard Work and Good Intentions Gotten Us?

- Microbiology Laboratory Policies: Maximizing the Impact

- What is the Track Record for Ha ndwa shing, Ba mier Techniques, and Isolation Policies?

- Do Antibiotic Management Programs Work?

Health Care Delivery: What Does the Future Hold? Featuring a Special Update on Current Political Realities of Health Care by Carol $H$. Rasco, Assistant to the President for Domestic Policy, The White House, Washington, DC

- Role of the JCAHO in Improving Health Care Quality as Delivery Systems Change.

- Impact of Health Care Delivery Changes on Quality Improvement Activities

- impact of Health Care Delivery Changes on the Hospital Epidemiologist

Tuberculosis

- Administrative Controls: Making the System Work

- Rapid Diagnostic Tests: How Good Are They and How Soon Will We Get Them?

- Environmental and Engineering Controls: Problems and Prospects

- Personnel Health Issues

SYMPOSIA:

Trends and Complications in Out of Hospital Care

- Hemodialysis

- Intravenous Therapy

- Child Day Care Health Issues

- Long-Term Care Facilities

Controversies in Prevention of Pediatric Nosocomial Infections

- Viral Infections: Role of Rapid Diagnosis, Isolation, and Prophylaxis in 1995

- Fungal Infections: Risk Factors, Prophylaxis, and Treatment

- Bacterial infections in Neonatal and Pediatric Critical Care Units: How to Prevent and Manage Infections with Resistant Organisms

- Coagulase-Negative Staphylococcat Bloodstream Infections: Risk Factors and Prevention 
Surgical Complications and Infections

- Mechanisms and Epidemiology of Prosthetic Joint Infections

- Changing Epidemiology of Nosocomial Infections in Bum Patients

- Trends in Complications of Laparoscopic Procedures

- Coronary Artery Bypass Grafts

\section{Bloodborne Infections}

- Hepatitis C Virus: Issues for the Hospital Ep idemiologist

- Unusual Cases of Bloodbome Pathogen Transmission:

Scientific Update and Implications for Prevention Recommendations

\section{Controversies in the Prevention of Device Related Infections in Patients}

- Upper Ainway Infections Associated with Nasal fntubation

- Current Developments, Controversies, and Myths Regarding Sterilization and Disinfection Strategies Used in Hospitals

- Point-Counterpoint: Resolved: Routine Intravascular Catheter Changes Reduce the Risk of Nosocomial Infection

\section{Antimicrobial Resistance in the Intensive Care Unit}

(supported by an educational grant from Zeneca Pharmaceuticals Group)

- Cross-resistance and Associated Resistance Mechanisms

- Trends in Antimic robial Resistance in Intensive Care Units

- Monitoring Resistance in the Intensive Care Unit

Personnel Health: What's New in 1995?

- Immunizations for Hea lth-ca re Workers

- Post-Exposure Management

- Selection, Implementation, and Evaluation of Safer Needle Devices

\section{Unusual Infections}

- Parasites

- Unusual Nosocomial Fungi: Lessons to be Leamed

- Recent Trends in Nosocomial Pseudoinfection

- Most Bizarre Nosocomial Infection(s)

Late Breaker Session:

Review and Explanation of the Recently Published CDC Guidelines for Prevention of Tuberculosis Transmission. In this session you will have the chance to ask one the authors of the CDC guidelines unique and pertinent questions.

William R. Jarvis, MD, Centers for Disease Control and Prevention, Atlanta, Georgia

- Ten Meet the Consultant Sessions where you can consult with specialists in your field of interest.

In The New HICPAC Guidelines for Prevention of Nosocomial Pneumonia and Control of Vancomycin Resistant Enterococci: Discussion with the Authors, and The New HICPAC Isolation Guidelines and Plans for Future HICPAC Guidelines you will have the opportunity to ask the authors of the CDC guidelines specific questions that affect how you and your peers accomplish your work. 


\section{The Society for Healthcare Epidemiology of America}

\section{SHEA/CDC/AHA \\ Training Course in Hospital Epidemiology}

\section{Program}

The program will be held May 6-9, 1995 at the Hyatt Regency Embarcadero, San Francisco, California. Timothy W. Lane, M.D., William Martone, M.D., and Gina Pugliese, R.N., M.S., will co-chair the program.

\section{Purpose}

This program, developed by the Society for Healthcare Epidemiology of America (SHEA), the Centers for Disease Control and Prevention (CDC), and the American Hospital Association (AHA), is intended for infectious disease fellows and new hospital epidemiologists. It emphasizes hands-on exercises in which participants work in small groups to detect, investigate, and control epidemiological problems encountered in the hospital setting. These work sessions are supplemented with lectures and seminars covering fundamental aspects of hospital epidemiology including epidemiology and surveillance, epidemic investigation, transmission and control of nosocomial infections, disinfection and sterilization, employee health, isolation systems, regulatory compliance, and quality improvement.

\section{Who Should Attend}

You should attend if you are a hospital epidemiologist or an infection control practitioner or if you are looking for a course that will provide you the most current information concerning infection control practices and epidemiological methods in health care. This fundamental program will provide you with the opportunities to find solutions to real situations that will occur in the hospital setting. Intensive problem solving sessions are supplemented with lectures and seminars presented by leading authorities.

\section{Scholarships}

Scholarships in the amount of $\$ 1,000$ will be awarded to up to ten infectious disease fellows for the program to defray the special course fee for fellows of $\$ 350$ and expenses incurred in attending the training program.

Interested fellows must submit a letter of no more than one page describing why they would like to have additional training in hospital epidemiology. A letter from the fellow's program director outlining the applicant's qualifications and suitability for the course also is required. The deadline for receipt of scholarship applications for the course is Wednesday, March 15. 1995.
The SHEA Educational Activities Committee will select the scholarship recipients based on review of these letters. Winners will be notified in late March, 1995.

\section{Nominations}

Please send scholarship applications to:

Timothy A. Lane, M.D.

c/o The Society for Healthcare Epidemiology of America

875 Kings Highway, Suite 200

Woodbury, NJ 08096-3172

\section{Fees}

Individual Registrants $\$ 495$

Fellows in Infectious Disease $\$ 350$

\section{Credits}

The Centers for Disease Control and Prevention (CDC) is accredited by the Accreditation Council for Continuing Medical Education to sponsor continuing medical education for physicians.

The Centers for Disease Control and Prevention designates this continuing * education activity for up to 21 hours in Category 1 of the Physician's . Recognition Award of the American Medical Association.

\section{General Course Information}

Information regarding the schedule, hotel and travel accommodations, " discount airfare, and course fees are available from SHEA (609) 845-1720. Note that application for a scholarship does not constitute enrollment in the program. This must be done separately.

Scholarship Awards provided in part by an educational grant from SmithKline Beecham

\section{SmithKline Beecham} Pharmaceuticals 